\title{
Effect of cue exposure, urge to smoke, and nicotine deprivation on cognitive performance in smokers
}

Citation for published version (APA):

Havermans, R. C., Debaere, S., Smulders, F. T., Wiers, R. W., \& Jansen, A. T. (2003). Effect of cue exposure, urge to smoke, and nicotine deprivation on cognitive performance in smokers. Psychology of Addictive Behaviors, 17(4), 336-339. https://doi.org/10.1037/0893-164X.17.4.336

Document status and date:

Published: 01/01/2003

DOI:

10.1037/0893-164X.17.4.336

Document Version:

Publisher's PDF, also known as Version of record

Document license:

Taverne

\section{Please check the document version of this publication:}

- A submitted manuscript is the version of the article upon submission and before peer-review. There can be important differences between the submitted version and the official published version of record.

People interested in the research are advised to contact the author for the final version of the publication, or visit the DOI to the publisher's website.

- The final author version and the galley proof are versions of the publication after peer review.

- The final published version features the final layout of the paper including the volume, issue and page numbers.

Link to publication

\footnotetext{
General rights rights.

- You may freely distribute the URL identifying the publication in the public portal. please follow below link for the End User Agreement:

www.umlib.nl/taverne-license

Take down policy

If you believe that this document breaches copyright please contact us at:

repository@maastrichtuniversity.nl

providing details and we will investigate your claim.
}

Copyright and moral rights for the publications made accessible in the public portal are retained by the authors and/or other copyright owners and it is a condition of accessing publications that users recognise and abide by the legal requirements associated with these

- Users may download and print one copy of any publication from the public portal for the purpose of private study or research.

- You may not further distribute the material or use it for any profit-making activity or commercial gain

If the publication is distributed under the terms of Article $25 \mathrm{fa}$ of the Dutch Copyright Act, indicated by the "Taverne" license above, 


\title{
Effect of Cue Exposure, Urge to Smoke, and Nicotine Deprivation on Cognitive Performance in Smokers
}

\author{
Remco C. Havermans, Saskia Debaere, Fren T. Y. Smulders, Reinout W. Wiers, and Anita T. M. Jansen \\ Maastricht University
}

\begin{abstract}
The primary aim of this investigation was to test the hypothesis that the urge to smoke interferes directly with cognitive performance. Fifty-four smokers were randomly assigned to 1 of 3 groups: (a) ad lib, (b) deprived, or (c) nicotine patch. Participants rated their urge to smoke on continuous visual analogue scales. Cognitive performance was determined by measuring reaction times (RTs) on a Sternberg task. The deprived group reported a higher urge and had longer RTs than the ad lib group when exposed to smoking-related cues. However, the nicotine patch group reported a higher urge in the absence of longer RTs. The results indicated that nicotine deprivation affects cognitive performance and that the urge to smoke only partially mediated RTs.
\end{abstract}

In 1990, Tiffany proposed a cognitive model of drug urges and drug use. According to Tiffany, drug use behavior becomes automatic because of frequent self-administration of drugs. Automatic drug use is represented in long-term memory as an action schema, and its execution can be triggered by a drug-related cue. According to the model, one experiences an urge when execution of the schema is impeded. In this case, effortful cognitive processes will be allocated to either ensure drug use or abstinence.

The assumption that urges reflect effortful cognitive processing can be tested by a dual-task procedure; in other words, the urge to use drugs should interfere with performance on a cognitive task (Tiffany, 1990). Some empirical support for this hypothesis has been found (e.g., Cepeda-Benito \& Tiffany, 1996; Gross, Jarvik, \& Rosenblatt, 1993; Sayette \& Hufford, 1994). However, it is conceivable that drug deprivation played an important, if not a crucial, role in such detrimental cognitive performance. In this study, we attempted to dissociate the effect of nicotine deprivation and urge to smoke on performance on a Sternberg task, a choice reaction time (RT) task that requires the individual to scan through working memory (Sternberg, 1975). This task gives an estimate not only of the duration of basic perceptual and motor processes, comparable to simple RT tasks, but also of the isolated duration of a capacitydemanding memory search (Sternberg, 1975). Therefore, the Sternberg task may be a more sensitive measure of the disrupting effects of urges on cognitive performance than a simple RT task.

By manipulating the variability of the intertrial intervals, we also investigated whether urges specifically disrupt performance when the task requires sustained attention. Long, variable intertrial intervals attenuate response preparedness, and thus require sustained attention (see Niemi \& Näätänen, 1981). Using such long and variable intertrial intervals, Sayette et al. (1994) found in

Remco C. Havermans, Saskia Debaere, Fren T. Y. Smulders, Reinout W. Wiers, and Anita T. M. Jansen, Faculty of Psychology, Experimental Psychology, Maastricht University, Maastricht, the Netherlands.

Correspondence concerning this article should be addressed to Remco C. Havermans, Faculty of Psychology, Experimental Psychology, Maastricht University, P.O. Box 616, 6200 MD Maastricht, the Netherlands. E-mail: r.havermans@psychology.unimaas.nl recovering alcoholics a particularly large effect on RT of the urge to drink alcohol.

In sum, the aim of the present study was to investigate the question of whether the urge to smoke directly affects performance on a cognitive task and, if it does, whether such an effect would be more pronounced when the task requires sustained attention.

\section{Method}

\section{Participants}

Fifty-four smokers (22 men and 32 women) with a mean age of 22.6 years $(S D=3.8$, range $=18-42)$ smoking at least 10 cigarettes a day $(M=18.5, S D=4.8$, range $=10-35)$ were recruited by posted advertisements. Each participant was paid fl. 20 (approximately \$9 U.S.) on completion of the experiment. Participant characteristics are listed in Table 1.

\section{Cognitive Performance}

Performance on the Sternberg task was measured using a computer with millisecond-timing capabilities. A memory set containing two, four, or six digits was presented before each block of trials. Participants first memorized this set. Next, a warning signal (a 500-ms computer-generated tone) signaled the presentation of a target digit in the center of the computer screen. The interval between warning signal and target is called a foreperiod. In the fixed-foreperiod condition, the interval between the warning signal and the target had a fixed duration of $2.5 \mathrm{~s}$. In the variable-foreperiod condition, this interval was varied randomly around a mean of $2.5 \mathrm{~s}$ and was nonaging. This ensures that the participant cannot predict the timing of the presentation of the target digit, hence the task requires sustained attention (Gottsdanker, Perkins, \& Aftab, 1986).

The participants' task was to decide whether the shown target digit belonged to the memory set. Participants responded by pushing either a "yes" or "no" key. Half of all participants in each group had the "yes" key on the left and the "no" key on the right of a response pad, and the other half had the opposite assignment. Each participant received a total of 144 trials, equally divided over six blocks that differed in memory set size and foreperiod. The order of presentation of these blocks was counterbalanced by a Latin square.

\section{Design and Procedure}

Participants were randomly assigned to one of three groups: (a) active, ad libitum smokers (ad lib), (b) smokers who had been abstinent for $12 \mathrm{hr}$ 
Table 1

Number of Participants, Mean Number of Consumed Cigarettes (Cig) Per Day, Mean Scores on the Fagerström Test of Nicotine Dependence (FTND), and Mean Carbon Monoxide (CO) Level in End-Expired Air for Each Group

\begin{tabular}{|c|c|c|c|c|c|c|}
\hline \multirow[b]{3}{*}{ Variable } & \multicolumn{6}{|c|}{ Group } \\
\hline & \multicolumn{2}{|c|}{$\begin{array}{c}\text { Ad lib } \\
(n=18)\end{array}$} & \multicolumn{2}{|c|}{$\begin{array}{l}\text { Deprived } \\
(n=18)\end{array}$} & \multicolumn{2}{|c|}{$\begin{array}{l}\text { Nicotine } \\
\text { patch } \\
(n=18)\end{array}$} \\
\hline & $M$ & $S D$ & $M$ & $S D$ & $M$ & $S D$ \\
\hline Cig/day & 17.5 & 4.6 & 18.1 & 4.1 & 19.8 & 5.7 \\
\hline FTND score & 3.6 & 2.1 & 4.6 & 2.0 & 4.5 & 2.0 \\
\hline CO level (ppm) & 16.2 & 6.9 & 11.1 & 1.6 & 11.1 & 3.0 \\
\hline
\end{tabular}

(deprived), or (c) 12-hr abstinent smokers wearing a transdermal nicotine patch (Nicotinell TTS 30, Lohmann Therapie Systeme, Andernach, Germany; nicotine patch group).

All participants signed informed consent forms before participating in the experiment and completed the Fagerström Test of Nicotine Dependence (Heatherton, Kozlowski, Frecker, \& Fagerström, 1991), a questionnaire containing six items concerning smoking behavior. Scores on this test range from 0 (not nicotine dependent) to 10 (highly nicotine dependent).

At arrival, a sample of end-expired air was taken from each participant and subsequently analyzed for carbon monoxide (CO) content with a Miran 1B infrared gas analyzer (FOXBORO, East Bridgewater, MA).

Next, each participant was asked to rate his or her urge to smoke on a single-item 100-mm visual analogue scale that ranged from 0 (no urge to smoke at all) to 100 (a near irresistible urge to smoke). This was Urge Measurement 1.

Participants practiced each of the six blocks of trials for $1 \mathrm{~min}$, with the experimenter monitoring performance. After this practice session, participants in the two smoking-abstinent groups (deprived and nicotine patch) were exposed to cues for approximately $6 \mathrm{~min}$. This exposure consisted of handling a cigarette of their favorite brand and to simulate smoking a burning cigarette. Participants from the ad lib group were instructed to smoke a cigarette. After simulated or real smoking, participants rated their urge to smoke (Urge Measurement 2), after which they had to perform on the Sternberg task. For participants from the deprived and nicotine patch groups, the experimenter sat within the left peripheral view of the participant and smoked cigarettes during the task. To control for his presence and movements, the experimenter played with a pen, occasionally taking notes, while participants from the ad lib group were performing on the task. After each block of trials, participants rated their urge to smoke (Urge Measurements 3-8). All experimental sessions were conducted between 9:00 a.m. and 11:00 a.m.

\section{Results}

\section{Manipulation Checks}

Figure 1 depicts the mean level of self-reported urge per group as rated by the participants throughout the experiment. We conducted contrast analyses to check whether the urge manipulations had led to differences in self-reported urge. These analyses showed a difference in urge between the ad lib group and the two smokingabstinent groups taken together (deprived + nicotine patch), $t(52)=10.0, p<.001$. Throughout the experiment, the abstinent smokers reported a larger urge than did the ad lib smokers. No difference in the extent of urge was found between the deprived and nicotine patch groups, $t(34)=0.5$, $n s$.

Participants' CO levels were assessed prior to the experiment. Smoking abstinence typically leads to a reduction in the level of $\mathrm{CO}$ in end-expired air. Thus, the active smokers should have had higher levels of CO than the abstinent smokers. Contrast analyses revealed a significant difference in the level of $\mathrm{CO}$ between the two smoking-abstinent groups taken together (deprived + nicotine patch) and the ad lib smokers, $t(52)=4.0, p<.001$. The level of $\mathrm{CO}$ was lower in the two smoking-abstinent groups compared with the level of $\mathrm{CO}$ in the active smokers, with no difference in the level of $\mathrm{CO}$ between the deprived and nicotine patch groups, $t(34)=0.1, n s$. Further inspection of individual CO levels in the two smoking-abstinent groups revealed exceptionally high scores in 4 participants (i.e., more than 1 standard deviation above the mean level of $\mathrm{CO}$ in their respective groups). One participant from the deprived group, and 1 participant from the nicotine patch group, had CO levels of $15 \mathrm{ppm}$, and 2 participants of the nicotine patch group had CO levels of $17 \mathrm{ppm}$. Because it is unlikely that these participants complied with the abstinence instruction, data from these participants were excluded from the following analyses.

\section{Influence of Urge and Nicotine Deprivation on Cognitive Performance}

Figure 2 depicts the mean RT in milliseconds of the correct responses on the Sternberg task for each group. RT latencies of the responses on the Sternberg task exceeding 2.5 standard deviations from average were considered probable outliers and were removed (see Ratcliff, 1993). We conducted a four-way analysis of variance with group (ad lib, deprived, or nicotine patch), response (positive or negative), set size (two, four, or six) and foreperiod (fixed or variable), with RT in milliseconds of the correct responses as the dependent variable.

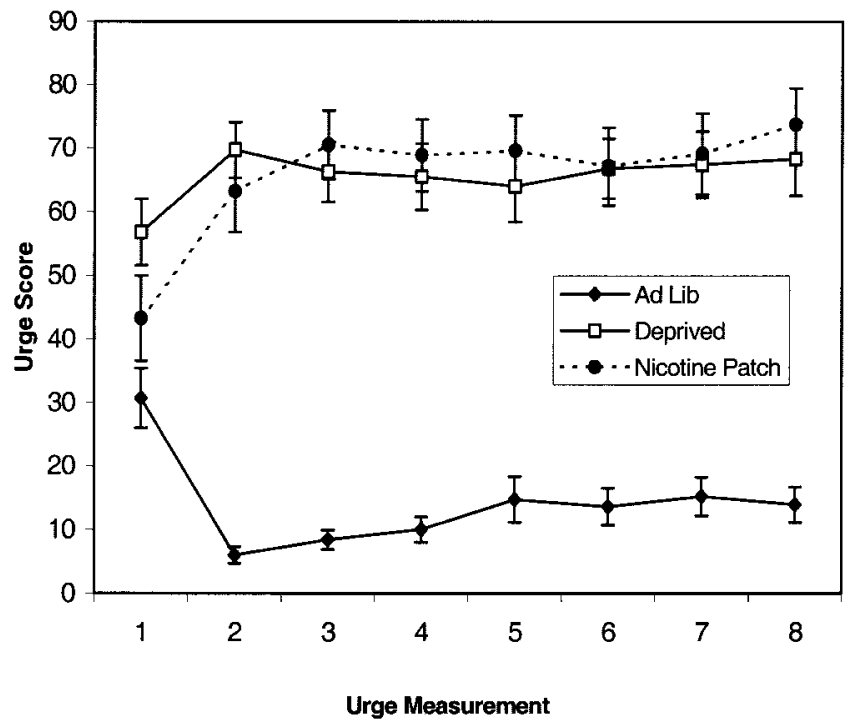

Figure 1. Mean level of self-reported urge $( \pm S E M)$ per urge measurement and for each separate group (ad lib, deprivation, and nicotine patch), as rated by the participants on visual analogue scales throughout the experiment. 


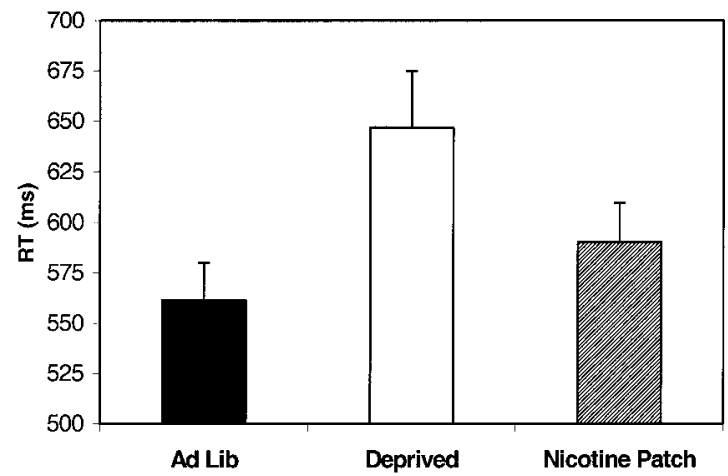

Figure 2. Mean reaction time (RT) in milliseconds of the participants' correct responses on the Sternberg memory search task $(+S E M)$ for each separate group (ad lib, deprivation, and nicotine patch).

A main effect of response was found, $F(1,47)=10.2, p<.01$. Positive responses were faster than negative responses. We also found a main effect of set size, $F(2,94)=118.2, p<.001$. This result reflects the increase in RT when the memory set is enlarged (consistent with Sternberg, 1975). As expected, there was a main effect of foreperiod, $F(1,47)=6.4, p<.05$, indicating that RT was larger when the foreperiod was variable. A main effect of group also was found, $F(2,47)=3.9, p<.05$. No interaction effects were found ( $p s>.10)$.

Post hoc Bonferroni-corrected contrast analyses revealed a significant difference in $\mathrm{RT}$ between the deprived group and the nondeprived participants (ad lib + nicotine patch), $t(48)=2.6$, $p<.025, d=0.8$. No difference in RT was found between the ad lib group and the participants from the nicotine patch + deprived groups, $t(48)=2.1, p=.04, d=0.6 .^{1}$

These results suggest that nicotine deprivation, rather than urge, affects cognitive performance. To test the hypothesis that the effect of nicotine deprivation on RT is mediated by the subjective urge to smoke, we conducted a mediation analysis as specified by Baron and Kenny (1986). First we tested the unmediated model to examine the effect of nicotine deprivation on RT. Participants were recoded as being nicotine deprived (deprived group) or not (ad lib + nicotine patch groups). We found that nicotine deprivation predicts RT latency $(\beta=.36), F(1,48)=6.9, p<.05$. Nicotinedeprived participants showed slower response times than the nondeprived participants.

Next, we tested the mediated model and found that nicotine deprivation predicted level of urge $(\beta=.44), F(1,48)=11.2, p<$ .01 . The urge to smoke predicted RT $(\beta=.32), F(1,48)=5.3$, $p<.05$. The direct effect of nicotine deprivation on RT became smaller (from .36 to .27) but remained significant, $F(1,48)=4.4$, $p<.05$, implying that the urge to smoke only partially mediates the effect of nicotine deprivation on RT. ${ }^{2}$

\section{Discussion}

The primary aim of this study was to test Tiffany's (1990) hypothesis that urges directly interfere with performance on a cognitive task. The results of the present study do not support this hypothesis. As long as nicotine is present, the urge to smoke shows relatively little interference with cognitive performance. This find- ing is in agreement with several recent studies that reported the absence of a strong relation between the urge to smoke and cognitive performance (see Baxter \& Hinson, 2001; Juliano \& Brandon, 1998). The secondary hypothesis of the present study was that a task requiring sustained attention is particularly troublesome for smokers experiencing urge. No support for this hypothesis was found. All participants showed slowing of RT in the variable-foreperiod condition.

The present results thus indicate that the observed differences in RT among the groups can be primarily ascribed to differences in nicotine deprivation, suggesting a purely psychopharmacological effect. However, an alternative explanation is that the urge to smoke affects RTs indirectly; that is, the urge to smoke affects cognitive performance only when one is nicotine deprived. This notion is in agreement with earlier findings by Sayette and Hufford (1994), who found an effect of the urge to smoke on RT only when the participants were both deprived from nicotine and exposed to smoking-related cues. This suggests that nicotine deprivation leads to attentional bias, which is expressed as detrimental cognitive performance when the nicotine-deprived smoker is exposed to smoking-related cues. Indeed, in the present experiment, the experimental manipulation affected memory scanning but only the basic attentional and motor processes, as reflected by the differences in RT. Although this account is a post hoc explanation for the present results, it agrees with the findings of several studies that investigated attentional bias for drug-related cues: Attentional bias is evident in drug-abstinent addicts, but not in nonabstinent addicts (e.g., Waters \& Feyerabend, 2000).

It should be noted that this study was conducted with a relatively small sample. The absence of an effect of urges on cognitive performance can be ascribed to a lack of power, as the detection of a small or medium effect would have required a larger sample size (see Cohen, 1992). The present findings show that if the urge to smoke does affect cognitive performance, it is most likely a medium effect. Furthermore, it is possible that the participants in the nicotine patch group had worn the patch for varying lengths of time. We did not control for this, and it may have attenuated the power of the analyses by adding more variance to the observations. Thus, more research is required to determine whether urges truly reflect nonautomatic cognitive processing. It is clear that the level of drug deprivation should be controlled.

\footnotetext{
${ }^{1}$ We conducted the same analyses including all participants and obtained the same pattern of results.

${ }^{2}$ We conducted the same mediation analysis including all participants and obtained the same pattern of results.
}

\section{References}

Baron, R. M., \& Kenny, D. A. (1986). The moderator-mediator variable distinction in social psychological research: Conceptual, strategic and statistical considerations. Journal of Personality and Social Psychology, 51, 1173-1182.

Baxter, B. W., \& Hinson, R. E. (2001). Is smoking automatic? Demands of smoking behavior on attentional resources. Journal of Abnormal Psychology, 110, 59-66.

Cepeda-Benito, A., \& Tiffany, S. T. (1996). The use of a dual-task procedure for the assessment of cognitive effort associated with cigarette craving. Psychopharmacology, 127, 155-163. 
Cohen, J. (1992). A power primer. Psychological Bulletin, 112, 155-159. Gottsdanker, R., Perkins, T., \& Aftab, J. (1986). Studying reaction time with nonaging intervals: An effective procedure. Behavior Research Methods, Instruments, \& Computers, 18, 287-292.

Gross, T. M., Jarvik, M. E., \& Rosenblatt, M. R. (1993). Nicotine abstinence produces content-specific Stroop interference. Psychopharmacology, 110, 333-336.

Heatherton, T. F., Kozlowski, L. T., Frecker, R. C., \& Fagerström, K. (1991). The Fagerström Test for Nicotine Dependence: A revision of the Fagerström Tolerance Questionnaire. British Journal of Addiction, 86, $1119-1127$.

Juliano, L. M., \& Brandon, T. H. (1998). Reactivity to instructed smoking availability and environmental cues: Evidence with urge and reaction time. Experimental and Clinical Psychopharmacology, 6, 45-53.

Niemi, P., \& Näätänen, R. (1981). Foreperiod and simple reaction time. Psychological Bulletin, 89, 133-162.

Ratcliff, R. (1993). Methods for dealing with reaction time outliers. Psychological Bulletin, 114, 510-532.
Sayette, M. A., \& Hufford, M. R. (1994). Effects of cue exposure and deprivation on cognitive resources in smokers. Journal of Abnormal Psychology, 103, 812-818.

Sayette, M. A., Monti, P. M., Rohsenow, D. J., Gulliver, S. B., Colby, S. M., Sirota, A. D., et al. (1994). The effects of cue exposure on reaction time in male alcoholics. Journal of Studies on Alcohol, 55, 629-633.

Sternberg, S. (1975). Memory scanning: New findings and current controversies. Quarterly Journal of Experimental Psychology, 27A, 1-32.

Tiffany, S. T. (1990). A cognitive model of urges and drug-use behavior: Role of automatic and non-automatic processes. Psychological Review, 97, 147-168.

Waters, A. J., \& Feyerabend, C. (2000). Determinants and effects of attentional bias in smokers. Psychology of Addictive Behaviors, 14, 111-120.

Received May 24, 2002

Revision received January 27, 2003

Accepted February 4, 2003

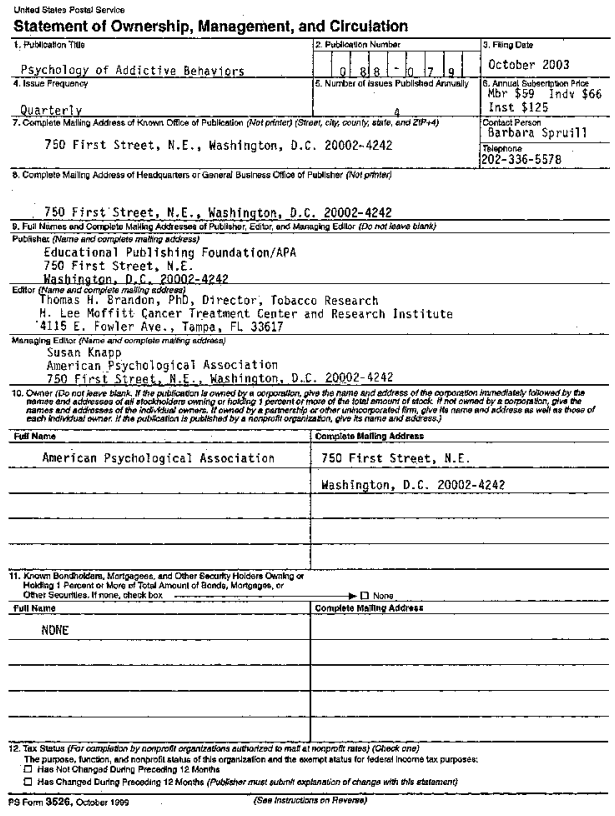

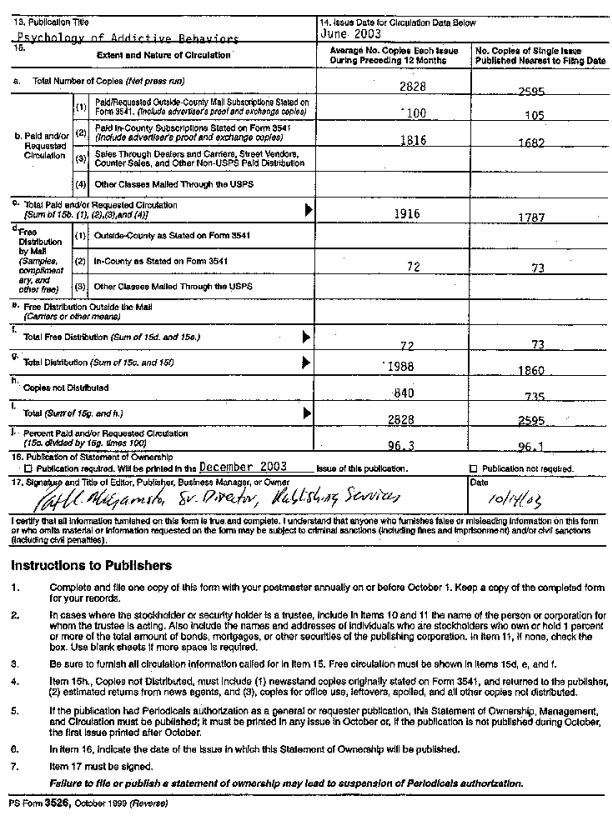

